\title{
An Unusual Presentation of Congenital Hypothyroidism in a Newborn: Transient Pseudo-Obstruction
}

\author{
Sirin Mneimneh", Mariam Rajab, Farah Hajar \\ Pediatrics Department, Makassed General Hospital, Beirut, Lebanon
}

"Corresponding Author: Dr. Sirin Mneimneh, Pediatric Department, Makassed General Hospital, Beirut, 00961, Lebanon

Received: 12 July 2018; Accepted: 02 August 2018; Published: 08 August 2018

\begin{abstract}
Congenital hypothyroidism is mostly asymptomatic at birth. It is usually detected by targeted neonatal screening for $\mathrm{CH}$ that is performed after birth. Nonetheless, there are reports of rare and vague presentations of $\mathrm{CH}$, as protracted icterus, abdominal distension, skin mottling, hypoactivity, poor feeding, muscle hypotonia, huge posterior fontanel, difficulty in breathing, hypothermia, peripheral cyanosis, abdominal distension, vomiting, and edema [1]. We report a preterm neonate that presented with abdominal distension with feeding intolerance, secondary to gastrointestinal hypomotility caused by congenital hypothyroidism.
\end{abstract}

Keywords: Congenital Hypothyroidism; Abdominal Distension; Newborn

\section{Case Report}

This was a 31 weeks female newborn, product of in vitro fertilization, due to male infertility, 2nd member of twin gestation. The parents were non-consanguineous and had negative family history concerning thyroid disorders. Mother presented at 31 weeks of gestation with preterm labor and was started on IV magnesium sulfate, but cessation of labor failed so urgent cesarean section was performed. Baby was born with Apgar score 8, 8 at 1 and 5 minutes respectively, and required transfer to NICU for prematurity. The birth weight was $1240 \mathrm{gm}$. She initially received nasal continuous positive airway pressure for mild respiratory distress and antibiotics (Ampicillin and Gentamicin) were started for suspected sepsis.

At day 3 of life, respiratory symptoms subsided feeding was initiated (breast milk) through oro-gastric tube. At the same day, patient started to develop bilious emesis in addition to abdominal distention. Physical examination revealed moderate fullness in the abdomen with sluggish bowel sounds. Sepsis work-up was unremarkable with normal serum electrolytes. Standing plain radiograph of the abdomen showed non-specific dilatation of small and 
large bowels. To note that the patient passed meconium at 48 hours of life. The patient was treated conservatively by intravenous fluids and nothing by mouth with open oro-gastric tube that gave bilious drainage. At day 5 of life the patient developed indirect hyperbilirubinemia which was treated by phototherapy. At day 7 of life screening for congenital hypothyroidism revealed thyroid stimulating hormone $\mathrm{TSH}$ level of $158.4 \mathrm{mIU} / \mathrm{mL}$ (normal=0.62-8 $\mathrm{mIU} / \mathrm{mL}$ ), and FT4 level of $4 \mathrm{pmol} / \mathrm{L}$ (normal=6.2-30 pmol/L).

The patient was then started on Levothyroxine $10 \mathrm{mcg} / \mathrm{kg} / \mathrm{day}$, 48 hours later, abdominal distension markedly improved and breast milk started to be tolerated. Repeated thyroid hormones 1 week after starting therapy showed a $\mathrm{TSH}=17 \mathrm{mIU} / \mathrm{mL}$ and FT4=23 pmol/l. Feeding was increased progressively with no further episodes of intolerance. The infant nursed well and was discharged home. Follow-up 2 weeks later revealed a healthy infant with normal FT4 and TSH.

\section{Discussion}

We report a newborn with congenital hypothyroidism $(\mathrm{CH})$ manifesting with striking gastrointestinal symptoms that resolved after treatment with L-thyroxin. Although abdominal distention has been described as one of the features of untreated hypothyroidism, tense tympanic distention of the abdomen with paralytic ileus or bilious emesis pointing to a possible intestinal obstruction, are rare manifestations [2-3]. Most infants who have thyroid dysgenesis are asymptomatic few have signs of hypothyroidism during the early weeks of life. Only about 5\% of hypothyroid infants are detected clinically before the chemical screening diagnosis is established [4].

The early manifestations of congenital hypothyroidism can be hypotonia, hyporeflexia, bradycardia, hypotension, anemia, widely patent cranial sutures, constipation, thick dry cold skin, long and abundant coarse hair, large tongue, abdominal distention, and umbilical hernia [5]. In the literature, gastrointestinal manifestations appeared during the first 2 weeks of life in the reported cases. Abdominal distension was the lonely early manifestation of the $\mathrm{CH}$ in our patient. Similarly to the patients reported in the literature, our patient developed the abdominal distension at day 7 of life.

Although there are multiple early manifestations of $\mathrm{CH}$, some of the signs and symptoms are not present till 6 to 12 weeks postnatally, especially lethargy, constipation, and the umbilical hernia. The cretinoid facies and growth retardation become increasingly obvious during the first several months of life [6]. The delayed appearance of typical features of hypothyroidism, has been related to the protective effects of the low levels of maternal thyroxin and a relatively delayed T4 dependency of selected tissues, even in athyroid neonate [7].

It is known that prematurity can affect thyroid function. Fetal thyroid system metabolism is characterized by relatively high circulating levels of TRH and TSH, immature thyroid gland FT4 biosynthesis and secretory process, limited effects of FT4 on responsive gene transcription events and immature FT4 feedback control of TSH secretion [8-10]. Although the prematurity could affect the thyroid function in our patient, the decrease in TSH level 1 week after treatment and the disappearance of clinical manifestations points toward congenital hypothyroidism. 
currently, no extensive studies have been performed in twin pregnancies to evaluate the occurrence of congenital hypothyroidism. There is 3-fold increased risk of congenital hypothyroidism in twins than in the general population. Based on a previously reported highly discordant twin series and the Italian congenital hypothyroidism twin population, the concordance for the disease was very low (4.3\%) [11-13]. The high discordance rate found in these studies demonstrates the importance of environmental factors that suggests the occurrence of non inheritable post zygotic events in the cause of congenital hypothyroidism [14]. In our case, congenital hypothyroidism was present only in one member of the twin gestation.

Thus we report unusually severe gastrointestinal manifestations in a premature newborn diagnosed with congenital hypothyroidism. Although most cases of congenital hypothyroidism are asymptomatic or mildly symptomatic at the time of diagnosis by the neonatal screening program, occasionally some neonates, especially those with more severe hypothyroxinemia, may have striking clinical features.

Finally, it is critical that the medical caregivers, general practitioner pediatricians to have have an enhanced understanding of the spectrum of clinical manifestations of congenital hypothyroidism to avoid delay in initiating therapy [15]. Table 1 summarizes the reported cases of $\mathrm{CH}$ manifested by gastrointestinal symptoms. To the best of our knowledge, our case is the fourth reported in the literature of $\mathrm{CH}$ manifested by intestinal hypomotility.

\begin{tabular}{|c|c|c|c|c|}
\hline Author & $\begin{array}{l}\text { Gestational } \\
\text { age }\end{array}$ & $\begin{array}{ll}\text { Age } & \text { at } \\
\text { diagnosis } & \end{array}$ & Clinical manifestations & $\begin{array}{l}\text { TSH value } \\
\text { (mIU/mL) }\end{array}$ \\
\hline Nasir AM, et al. [16] & 36 weeks & Day 7 of life & $\begin{array}{l}\text { 1. abdominal distention } \\
\text { 2. delayed passage of meconium } \\
\text { 3. indirect hyperbilirubinemia }\end{array}$ & 413 \\
\hline $\begin{array}{l}\text { Aniruddha SV, et al. } \\
\text { [17] }\end{array}$ & 35 weeks & Day 12 of life & $\begin{array}{ll}\text { 1. } & \text { mild abdominal fullness } \\
\text { 2. } & \text { bilious emesis } \\
\text { 3. } & \text { hypoactive bowel sounds }\end{array}$ & $>1000$ \\
\hline $\begin{array}{l}\text { Tatiana Smolkin, et } \\
\text { al. [18] }\end{array}$ & Full term & Day 4 of life & 1. abdominal distention & $>400$ \\
\hline Our case & 31 weeks & Day 7 of life & $\begin{array}{l}\text { 1. mild abdominal fullness } \\
\text { 2. bilious emesis } \\
\text { 3. indirect hyperbilirubinemia }\end{array}$ & 158 \\
\hline
\end{tabular}

Table 1: Reported cases of unusual gastrointestinal presentation of $\mathrm{CH}$.

\section{Conflict of Interest}

No 


\section{References}

1. Virtanen M. Manifestations of congenital hypothyroidism during the 1st week of life. Eur J Pediatr 147 (1988): 270-274.

2. DiGeorge A, Behrman RE, Kliegman RM, et al. Disorders of the thyroid gland. Nelson Textbook of Pediatrics. 14th ed. Philadelphia WB Saunders (1991): 1416-1420.

3. Opitz JC. Congenital hypothyroidism presenting as functional bowel obstruction in the premature infant. Wis Med 78 (1979): 23-25.

4. Tachman ML. Hypothyroidism diversity of presentation. Endocr Rev 5 (1984): 456-465.

5. Polak M. Hyperthyroidism in early infancy pathogenesis clinical features and diagnosis with a focus on neonatal hyperthyroidism. Thyroid (1998): 1171-1177.

6. Sureka Bollepallz. Avery's Diseases of the Newborn. $9^{\text {th }}$ (Edn) (2012): 1312.

7. Polk DH. Fetal and neonatal thyroid physiology. In: Polin RA, Fox WW, Fetal and Neonatal Physiology. $2^{\text {nd }}$ (Edn) Philadelphia: WB Saunders (1997): 2460-2467.

8. Fisher DA. Hypothyroxinemia in premature infants: is thyroxine treatment necessary?. Thyroid 7 (1999): 715-720.

9. Fisher DA, Polk DH, Wu SY, et al. Fetal thyroid metabolism: a pluralistic system. Thyroid 4 (1994): 367371.

10. Thorpe Beeston JG, Nicolaides KH, McGregor AM, et al. Fetal thyroid function. Thyroid 2 (1992): 207 217.

11. Larson C. Risk factors associated with delayed thyrotropin elevations in congenital hypothyroidism. J Pediatr 143 (2003): 587-591.

12. Medda E. Risk factors for congenital hypothyroidism results of a population case-control study. Eur J Endocrinol 153 (1997): 765-777.

13. Waller DK. Risk factors for congenital hypothyroidism an investigation of infants birth weight, ethnicity and gender in California. Teratology 62 (2000): 36-41.

14. Corchia C. What proportion of multiple births is due to ovulation induction? A register-based study in Italy. Am J Pub Health 86 (1996): 851-854.

15. Aniruddha S. An Unusual Presentation of Congenital Hypothyroidism. A Report of Two Cases. Journal of Pediatric Gastroenterology and Nutrition 31 (2000): 198-200.

16. Nasir A, Jurayyan Al. Transient Functional Intestinal Obstruction In A Newborn. The First Clinical Manifestation of Congenital Hypothyroidism. Curr Pediatr Res 15 (2011): 101-103.

17. Tatiana Smolkin. Rare Presentations of Congenital Hypothyroidism. Isr Med Assoc J 13 (2011): 779-780.

Citation: Sirin Mneimneh. An Unusual Presentation of Congenital Hypothyroidism in a Newborn: Transient Pseudo-Obstruction. Journal of Pediatrics, Perinatology and Child Health 2 (2018): 6-9.

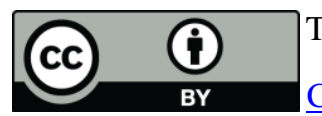

This article is an open access article distributed under the terms and conditions of the

Creative Commons Attribution (CC-BY) license 4.0 